\title{
Neoadjuvant hepatic arterial infusion chemotherapy for resectable hepatocellular carcinomas
}

\author{
Rina Tsutsui ${ }^{1}$, Hiroaki Nagamatsu², Osamu Itano ${ }^{3}$, Akihiro Deguchi $^{4}$, Tsubasa Tsutsumi ${ }^{5}$, Mamoru Hiraki $^{6}$, \\ Naohisa Mizukami ${ }^{7}$, Jun Akiba ${ }^{8}$ \\ 'Department of Digestive and Transplantation Surgery, Tokyo Medical University Hachioji Medical Center, Tokyo 193-0998, Japan. \\ ²Department of Gastroenterology, Juntendo University Hospital, Tokyo 113-8431, Japan. \\ ${ }^{3}$ Department of Hepato-Biliary-Pancreatic and Gastroenterological Surgery, International University of Health and Welfare School of \\ Medicine, Chiba 286-8686, Japan. \\ ${ }^{4}$ Department of Medicine, Kagawa Rosai Hospital, Kagawa 763-0013, Japan. \\ ${ }^{5}$ Department of Medicine, Kurume University School of Medicine, Fukuoka 830-0011, Japan. \\ ${ }^{6}$ Department of Surgery, Yame General Hospital, Fukuoka 834-0034, Japan \\ ${ }^{7}$ Department of Radiology, Yame General Hospital, Fukuoka 834-0034, Japan \\ ${ }^{8}$ Department of Pathology, Kurume University School of Medicine, Fukuoka 830-0011, Japan.
}

Correspondence to: Dr. Hiroaki Nagamatsu, Department of Gastroenterology, Juntendo University Hospital, 3-1-3 Hongo, Bunkyo-ku, Tokyo 113-8431, Japan. E-mail: h-nagamatsu@juntendo.ac.jp

How to cite this article: Tsutsui R, Nagamatsu H, Itano O, Deguchi A, Tsutsumi T, Hiraki M, Mizukami N, Akiban J. Neoadjuvant hepatic arterial infusion chemotherapy for resectable hepatocellular carcinomas. Hepatoma Res 2018;4:13.

http://dx.doi.org/10.20517/2394-5079.2018.20

Received: 15 Mar 2018 First Decision: 10 Apr 2018 Revised: 3 May 2018 Accepted: 7 May 2018 Published: 11 May 2018

Science Editor: Guang-Wen Cao Copy Editor: Guang-Zhe Zhu Production Editor: Huan-Liang Wu

\begin{abstract}
Aim: To evaluate the effect of neoadjuvant hepatic arterial infusion chemotherapy (HAIC) on the survival of patients with resectable hepatocellular carcinoma (HCC).

Methods: Between January 2003 and January 2014, 80 patients underwent hepatic resection for HCC. Of these patients, we evaluated 49 patients who met the following inclusion criteria: (1) preserved liver function (ChildPugh A); (2) resectable HCC ( $\leq 3$ nodules, regardless of the size); and (3) HCC with high-grade malignant potential. Among them, 13 patients underwent neoadjuvant HAIC and curative hepatectomy (treatment group). The remaining 36 patients underwent curative hepatic resection without neoadjuvant therapy (control group). Survival after hepatic resection was compared retrospectively between the groups.
\end{abstract}

Results: During follow-up, 2 (15.4\%) patients in the treatment group and 25 (69.4\%) patients in the control group developed recurrence. The $1-, 3-$, and 5 -year disease-free rates $(100 \%, 78.6 \%$, and $78.6 \%$, respectively vs. $65.8 \%$, $33.7 \%$, and $26.6 \%$, respectively; $P=0.003)$ and overall survival rates $(100 \%, 100 \%$, and $100 \%$, respectively vs. $91.7 \%, 77.8 \%$, and $55.3 \%$, respectively; $P=0.037$ ) were significantly better in the treatment group than in the control group.

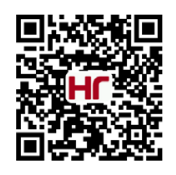


Conclusion: Neoadjuvant HAIC decreased the risk of recurrence and improved survival in patients with HCC with high malignant potential.

Keywords: Hepatocellular carcinoma, transcatheter arterial chemoembolization, hepatic arterial infusion chemotherapy

\section{INTRODUCTION}

Surgery is the standard treatment for hepatocellular carcinoma (HCC), which offers a chance of cure with preservation of liver function ${ }^{[1]}$ and achieves the best outcome (5-year survival rate of $\left.33 \%-60 \%\right)^{[2]}$. However, after curative liver resection for HCC, the incidence of recurrence in the remnant liver is as high as $60 \%$ within 3 years ${ }^{[3-5]}$. Among all cases of recurrence, approximately $90 \%$ are intrahepatic recurrences, which contribute to the high mortality rate in patients with $\mathrm{HCC}^{[6-9]}$. The risk factors for early-phase recurrence of HCC depend on the malignant potential of the tumor, including the presence of microscopic vascular invasion (MVI), serum alpha-fetoprotein (AFP) levels, tumor number, and tumor size ${ }^{[3,10,11]}$. Among these, the presence of MVI is an important risk factor affecting survival throughout the entire postoperative period $^{[12]}$, and the gross classification of HCC predicts the presence of MVI ${ }^{[13]}$.

Some studies demonstrated that preoperative transarterial chemoembolization (TACE) improved prognosis in select patients, such as those with preserved liver function and advanced-stage HCC $^{[14-17]}$. However, according to the 2012 European Association for the Study of the Liver (EASL) and European Organization for Research and Treatment of Cancer clinical practice guidelines, neoadjuvant chemoembolization has not proven to improve the outcomes of patients who underwent resection ${ }^{[1]}$. Additionally, neoadjuvant TACE is associated with the disadvantages of delaying surgery and increasing complications during surgery because of inflammatory pediculitis, perihepatic adhesions, or arterial thrombosis; moreover, if the tumor fails to respond to therapy, it continues to grow and becomes incurable ${ }^{[18,19]}$. Moreover, TACE also has the potential to cause adverse effects on liver function. Hepatic arterial infusion chemotherapy (HAIC) may sometimes be chosen as a therapeutic option for advanced HCC because of poor liver function. It allows the direct delivery of high doses of chemotherapeutic agents to the tumor site and reduces the systematic concentration of chemotherapeutic agents to a low level, which may result in a lower incidence of adverse drug reactions and early appearance of the chemotherapeutic effects in the early stage of treatment.

In this retrospective study, we evaluated the safety, feasibility, and surgical complications of neoadjuvant HAIC, and investigated the effect of it on survival without recurrence after resection of the lesion.

\section{METHODS}

\section{Patients}

Between January 2003 and January 2014, 80 patients underwent hepatic resection for HCC at our hospital. Of these patients, we investigated 49 patients who met the following inclusion criteria: (1) preserved liver function (Child-Pugh A); (2) resectable HCC ( $\leq 3$ nodules, regardless of the size); and (3) HCC with highgrade malignant potential. High-grade malignant potential refers to HCC with MVI. The patients were diagnosed on the basis of fan-shaped portal perfusion defects, which appeared in the periphery of the tumor on computed tomography (CT) scans during arterial portography and showed tumorous arterioportal shunts caused by microscopic portal vascular invasion. In terms of gross appearance, the simple nodular type with extranodular growth or confluent multinodular type predicted the presence of $\mathrm{MVI}^{[13,20]}$.

Of the 49 patients, 13 patients who were preoperatively diagnosed as having HCC with high-grade malignant potential, between June 2009 to January 2014, were treated with neoadjuvant HAIC (treatment group). 
Another 36 patients who met the inclusion criteria, between January 2003 and May 2009, had a curative hepatic resection (control group). This was a retrospective study of HCC patients at Yame General Hospital. The institutional review board approved this study, and written informed consent was obtained from the treatment group. Regarding the control group, the Ethics Committee waived the requirement for ethical approval and informed consent due to the retrospective nature of the study.

\section{Preoperative evaluation}

Baseline imaging examinations [CT angiography, dynamic CT, or/and dynamic contrast-enhanced magnetic resonance imaging (MRI)] were performed before surgery. HCC was confirmed when at least 2 radiographic images revealed the hallmarks of HCC or 1 radiographic image revealed the hallmarks of HCC together with AFP levels $>400 \mathrm{ng} / \mathrm{mL}^{[1]}$. HCC staging was performed according to the Barcelona clinic liver cancer (BCLC) staging classification ${ }^{[21,22]}$ and the 6th edition of the American Joint Committee on Cancer staging system of tumor nodes metastasis. Laboratory blood tests, including tests for hepatitis B surface antigen, hepatitis C virus antibodies, serum AFP, serum des-gamma-carboxyprothrombin (DCP), serum albumin, serum total bilirubin, serum aspartate aminotransferase (AST), serum alanine aminotransferase (ALT), prothrombin time, C-reactive protein, and platelet counts, were performed.

\section{Neoadjuvant hepatic arterial infusion chemotherapy protocol}

In the treatment group, a temporary indwelling catheter system ${ }^{[23]}$ was implanted via the left brachial artery under fluoroscopic guidance and was used for HAIC. A polyurethane-covered catheter, called anthron P-U catheter (APUC), 5 Fr $(100 \mathrm{~cm}$ ) (Toray Medical Co., Ltd., Tokyo, Japan) with a tapered tip (5- and 3.3-French outer diameters of the shaft and tip, respectively, and 0.035-/0.021-in inner diameters of the shaft and tip, respectively) was used as the indwelling catheter. This catheter was $100-\mathrm{cm}$ long and tapered to a 3.3-French microcatheter $60 \mathrm{~cm}$ from the tip. The tip of the catheter was inserted into the right or left hepatic artery, corresponding to the side on which the main tumor was located, via the celiac artery. In the case of multiple tumors, one or two side holes were manually created with a surgical knife to supply the rest of the tumor with chemotherapeutic agents.

The treatment regimen included low-dose 5-fluorouracil (5-FU) and cisplatin (low-dose FP), specifically, the regimen featured daily administration of cisplatin $(10 \mathrm{mg}$ for $30 \mathrm{~min})$ and a subsequent infusion of 5-FU (250 mg for $3 \mathrm{~h}$ ) on days 1-10. We named this treatment regimen as 2 weeks of low-dose FP. After the administration of chemotherapeutic agents, the catheter was removed under fluoroscopic guidance. No prophylactic antibiotics were administered during the catheter placement.

Laboratory variables were assayed once in several days, and the tumor marker was measured before and after the treatment regimen. HAIC was discontinued or reduced in case of adverse events higher than grade $3 / 4$ of the common terminology criteria for adverse events (CTCAE).

\section{Surgical procedure}

Curative liver resection was performed after a mean delay of $24 \pm 12$ days after catheter removal. A single surgeon performed all surgeries. Anatomic resection was defined as hemihepatectomy, extended hemihepatectomy, sectionectomy, or segmentectomy, and all other non-anatomic resections were classified as partial resections.

To determine the operative outcome, data regarding the operative time, intraoperative blood loss, red blood cell transfusion, complications, type of resection, hospital mortality, and hospital stay were collected for both groups.

\section{Pathologic assessment}

Two senior pathologists reviewed each specimen for histologic confirmation of the diagnosis. Clinicopathologic data such as tumor size recorded as the maximum diameter, vascular invasion, intrahepatic metastasis, gross 
classification, histologic grade, and the degree of liver cirrhosis were collected. The therapeutic effect was classified into 4 categories based on the Japanese breast cancer society criteria ${ }^{[24]}$.

\section{Follow-up}

Laboratory variables such as serum AFP, serum DCP, serum albumin, serum total bilirubin, serum AST, serum ALT, prothrombin time, and C-reactive protein levels and platelet counts were measured for both groups on postoperative days $1,3,7$, and 30 .

After discharge from our hospital, all patients were followed up in the outpatient clinic. Ultrasonography, 4-phase CT, or dynamic contrast-enhanced MRI was performed every 2 to 3 months, and serologic tests such as AFP and DCP measurements were performed at that time. In cases of recurrence, the patients were treated accordingly.

Survival was defined as the time from surgery to death, and disease-free survival (DFS) was defined as the time from surgery to either recurrence or death. Patients who were alive and free of recurrence at the end of follow-up were censored for $\mathrm{DFS}^{[22]}$.

\section{Statistical analysis}

Continuous data were presented as the mean \pm standard deviation or median and range and were compared using the $t$-test or Mann-Whitney's $U$ test, respectively. Categorical data were compared using Pearson's $\chi^{2}$ test or Fisher's exact test, as appropriate.

The Kaplan-Meier method was used to calculate the survival curves, and the log-rank test was used to assess the prognostic predictors of DFS. Variables with $P<0.10$ in univariate analysis were included in the multivariate analysis.

Differences were considered significant when the 2 -sided $P$-value was $<0.05$. Descriptive statistical analyses were performed using the IBM statistical package for the social sciences, version 20.0 (SPSS, IBM Co., Armonk, NY, USA).

\section{RESULTS}

The baseline characteristics of the patients are shown in Table 1. No significant differences were observed between the 2 groups.

\section{Outcomes and complications associated with neoadjuvant HAIC}

In the treatment group, all catheterization procedures were performed without critical complications. The median procedure time for implantation of the system was $80 \mathrm{~min}$ (range 43-180 min). The system was successfully implanted and used for treatment in all patients. The median catheter dwell time was 10 days (range 9-13 days). The median time to surgery after catheter removal was 21 days (range 12-34 days). Major complications associated with a temporary indwelling catheter system, such as hematoma, bleeding, hepatic arterial occlusion, dislocation of the catheter, and thrombosis, did not occur. Infection was suspected in 1 patient $(7.7 \%)$, and fever and flares in the left brachial artery appeared 8 days after the procedure in this patient. The patient's symptoms improved soon after catheter removal, which was 9 days after the chemotherapy [Table 2]. One patient (7.7\%) experienced CTCAE grade 2 gastritis. The most common side effects were nausea and loss of appetite; however, these symptoms were mostly CTCAE grade $1 / 2$, and they resolved after chemotherapy was completed.

The mean plasma AFP and DCP levels tended to decrease following neoadjuvant HAIC $(415.3 \pm 1086 \mathrm{ng} / \mathrm{mL}$ and $451.4 \pm 892.4 \mathrm{mg} / \mathrm{mL}$, respectively, prior to HAIC $v s .158 .8 \pm 404.7 \mathrm{ng} / \mathrm{mL}$ and $118.0 \pm 237.9 \mathrm{mg} / \mathrm{mL}$, respectively, after HAIC; $P=0.468$ and $P=0.243$, respectively), but the differences were not significant. No 
Table 1. Patient characteristics, baseline liver function, and tumor characteristics: treatment group versus control group

\begin{tabular}{llll}
\hline Variables & $\begin{array}{c}\text { Treatment group } \\
(\boldsymbol{n = 1 3 )}\end{array}$ & $\begin{array}{c}\text { Control group } \\
(\boldsymbol{n = 3 6 )}\end{array}$ & $\begin{array}{c}\boldsymbol{P} \\
\text { Age (years) }\end{array}$ \\
Gender (male/female) & $69(50-81)$ & $74(50-78)$ & 0.128 \\
Etiology & $10 / 3$ & $29 / 7$ & 1.000 \\
Hepatitis B carrier & & 6 & 0.298 \\
Hepatitis C carrier & 1 & 22 & \\
Others & 11 & 8 & 0.054 \\
Cirrhotic liver & 1 & 16 & 0.481 \\
Child-Pugh score at time of hepatectomy & 10 & $5.0(5.0-6.0)$ & 0.504 \\
AFP level (ng/mL)* & $5.0(5.0-6.0)$ & $14.3(2.0-2720.0)$ & 0.548 \\
DCP level (ng/mL)* & $6.6(2.0-3921.0)$ & $74(1.0-5940)$ & 0.666 \\
Tumor diameter (mm)* & $130(13-3252)$ & $25.0(10.0-58.0)$ & 0.708 \\
Tumor number & $27.0(14.0-50.0)$ & $1(1-3)$ & 1.000 \\
Presence of portal vein tumor thrombosis (Vp2-4) & $1(1-2)$ & 0 & 0.411 \\
Presence of satellite nodules & 0 & 12 & 0.278 \\
TNM pathological staging (stage I/II/IIIA/IIIB/IIIC/IV) & 6 & $15 / 19 / 2 / 0 / 0 / 0$ & \\
\hline
\end{tabular}

*Median with range. AFP: alpha-fetoprotein; DCP: des-gamma-carboxyprothrombin; TNM: tumor nodes metastasis [6th edition of the American Joint Committee on Cancer (AJCC) staging]

Table 2. Outcomes of temporary indwelling catheter system implantation: treatment group

\begin{tabular}{ll}
\hline Variables & $\boldsymbol{n}$ \\
\hline $\begin{array}{l}\text { Puncture region } \\
\text { (left brachial artery/right femoral artery/others) }\end{array}$ & $13 / 0 / 0$ \\
Procedure time (min)* & $80(43-180)$ \\
Number of catheter days (day)* & $10(9-13)$ \\
Time to operation from procedure (day)* & $21(12-34)$ \\
Complications & $1(7.7 \%)$ \\
Procedure-related complications & \\
hematoma formation & 0 \\
Complications during chemotherapy & \\
Hepatic arterial occlusion & 0 \\
Gastroduodenal ulcer & 0 \\
Cerebral infarction & 0 \\
Infection & 1 \\
Catheter dysfunction & \\
Catheter dislodgement & 0 \\
Occlusion of catheter & 0 \\
\hline
\end{tabular}

${ }^{\star}$ Median with range

liver function impairment and liver failure occurred after HAIC, and all patients underwent hepatectomy as expected [Table 3].

\section{Operative and perioperative outcome}

The operative outcomes and perioperative changes in liver function are presented in Tables 4 and 5. All patients with liver function impairment recovered. No adverse effect on liver function attributable to HAIC occurred after surgery. There was no difference in the operative outcomes of the 2 groups, and no hospital mortality was observed.

\section{Pathologic assessment}

The histopathologic findings of the resected livers are shown in Table 6. The histologic grade for patients in the treatment group after treatment was determined to be grade 0 for 3 patients (23\%), grade 1a for 3 patients (23\%), grade $1 \mathrm{~b}$ for 3 patients (23\%), grade $2 \mathrm{a}$ for 2 patients (15\%), grade $2 \mathrm{~b}$ for 1 patient ( $8 \%$ ), and grade 3 for 1 patient (8\%). 
Table 3. Preoperative liver function and tumor marker levels in the treatment group

\begin{tabular}{llcc}
\hline Variables & Before HAIC & Before operation & $\boldsymbol{P}$ \\
\hline Total bilirubin $(\mathrm{mg} / \mathrm{dL})$ & $0.6(0.3-1.1)$ & $0.6(0.3-0.8)$ & 0.511 \\
Serum albumin $(\mathrm{g} / \mathrm{dL})$ & $4.3(3.7-4.9)$ & $4.1(3.4-5.1)$ & 0.448 \\
Serum AST $(\mathrm{U} / \mathrm{L})$ & $32(18-99)$ & $31(20-58)$ & 0.762 \\
Serum ALT $(\mathrm{U} / \mathrm{L})$ & $34(9.0-120)$ & $32(12-61)$ & 0.801 \\
Prothrombin time $(\%)$ & $88(72-105)$ & $92(78-120)$ & 0.336 \\
Platelet $\left(\times 10^{4} / \mu \mathrm{L}\right)$ & $15.8(11.3-27.0)$ & $13.1(10.2-22.1)$ & 0.204 \\
C-reactive protein $(\mathrm{mg} / \mathrm{dL})$ & $0.05(0.01-0.18)$ & $0.06(0.04-0.60)$ & 0.418 \\
AFP level $(\mathrm{ng} / \mathrm{mL})$ & $6.6(2.0-3921)$ & $9.7(2.4-1365)$ & 0.776 \\
DCP level $(\mathrm{ng} / \mathrm{mL})$ & $130(13-3252)$ & $54(12-832)$ & 0.106 \\
\hline
\end{tabular}

All data shown as median with range. HAIC: hepatic arterial infusion chemotherapy; AST: aspartate aminotransferase; ALT: alanine aminotransferase; AFP: alpha-fetoprotein; DCP: des-gamma-carboxyprothrombin

Table 4. Intraoperative and postoperative outcomes of hepatectomy: treatment group versus control group

\begin{tabular}{lccc}
\hline Variables & Treatment group $(\boldsymbol{n}=\mathbf{1 3})$ & Control group $(\boldsymbol{n}=\mathbf{3 6})$ & $\boldsymbol{P}$ \\
\hline Operative duration $(\mathrm{min})^{\star}$ & $355(125-465)$ & $316(127-590)$ & 0.389 \\
Intraoperative blood loss $(\mathrm{mL})^{\star}$ & $860(41-2582)$ & $528(150-3320)$ & 0.118 \\
Red blood cells transfusion & 4 & 3 & 0.070 \\
Anatomical hepatectomy & 11 & 31 & 0.608 \\
Complications & & & 0.663 \\
Postoperative hemorrhage & 0 & 1 & \\
Bile leak & 0 & 0 & \\
Subphrenic collection & 0 & 1 & \\
Wound infection & 0 & 0 & \\
Transient liver impairment & 0 & 1 & \\
Ascites & 0 & 0 & \\
lleus & 1 & $12(8-20)$ & 0.297 \\
Hospital mortality & 0 & & \\
Hospital stay & $12(9-25)$ & & \\
\hline
\end{tabular}

${ }^{\star}$ Median with range

\section{Survival}

During the follow-up period, $2(15.4 \%)$ patients in the treatment group and $25(69.4 \%)$ patients in the control group experienced recurrence. The pattern of initial recurrence in the treatment group revealed that 1 patient each had intrahepatic recurrence and simultaneous intrahepatic and extrahepatic recurrence (multiple bone metastases).

The 1-, 3-, and 5-year DFS rates were 100\%, 78.6\%, and 78.6\%, respectively, for the treatment group and $65.8 \%, 33.7 \%$, and $26.6 \%$, respectively, for the control group. The DFS rates were significantly better in the treatment group than in the control group $(P=0.003)$ [Figure 1]. The 1-, 3-, and 5-year overall survival (OS) rates were $100 \%, 100 \%$, and $100 \%$, respectively, for the treatment group and $91.7 \%, 77.8 \%$, and $55.3 \%$, respectively for the control group, respectively. The OS rates were significantly better in the treatment group than in the control group $(P=0.037)$ [Figure 2].

The results of univariate analyses of the predictors of DFS are shown in Table 7. Using factors identified as significantly associated with DFS, multivariate analyses revealed that neoadjuvant HAIC $[P=0.039$, hazard ratio $(\mathrm{HR})=0.215$; 95\% confidential interval $(\mathrm{CI})=0.050-0.928]$, age $(P=0.017, \mathrm{HR}=0.374 ; 95 \% \mathrm{CI}=0.166$ $0.842)$, and tumor number $(P<0.001, \mathrm{HR}=7.731 ; 95 \% \mathrm{CI}=2.474-14.161)$ were independent predictors of DFS [Table 7].

\section{DISCUSSION}

The present study evaluated the effect of neoadjuvant HAIC for patients who had HCC with high malignant 
Table 5. Postoperative liver function: treatment group versus control group

\begin{tabular}{|c|c|c|c|c|c|c|c|c|c|c|c|c|}
\hline & \multicolumn{3}{|c|}{1 POD } & \multicolumn{3}{|c|}{3 POD } & \multicolumn{3}{|c|}{7 POD } & \multicolumn{3}{|c|}{1 POM } \\
\hline & $\begin{array}{c}\text { Treatment } \\
\text { group } \\
(n=13)\end{array}$ & $\begin{array}{l}\text { Control } \\
\text { group } \\
(n=36)\end{array}$ & $\boldsymbol{P}$ & $\begin{array}{c}\text { Treatment } \\
\text { group } \\
(n=13)\end{array}$ & $\begin{array}{l}\text { Control } \\
\text { group } \\
(n=36)\end{array}$ & $\boldsymbol{P}$ & $\begin{array}{c}\text { Treatment } \\
\text { group } \\
(n=13)\end{array}$ & $\begin{array}{l}\text { Control } \\
\text { group } \\
(n=36)\end{array}$ & $\boldsymbol{P}$ & $\begin{array}{l}\text { Treatment } \\
\text { group } \\
(n=13)\end{array}$ & $\begin{array}{l}\text { Control } \\
\text { group } \\
(n=36)\end{array}$ & $\boldsymbol{P}$ \\
\hline $\begin{array}{l}\text { Total } \\
\text { bilirubin } \\
(\mathrm{mg} / \mathrm{dL})\end{array}$ & $1.77 \pm 0.96$ & $1.69 \pm 0.89$ & 0.801 & $1.40 \pm 0.70$ & $1.44 \pm 0.78$ & 0.867 & $0.90 \pm 0.26$ & $0.87 \pm 0.34$ & 0.770 & $0.65 \pm 0.28$ & $0.68 \pm 0.30$ & 0.594 \\
\hline $\begin{array}{l}\text { Serum } \\
\text { albumin } \\
\text { (g/dL) }\end{array}$ & $3.65 \pm 0.29$ & $3.50 \pm 0.37$ & 0.206 & $3.61 \pm 0.29$ & $3.35 \pm 0.45$ & 0.069 & $3.40 \pm 0.25$ & $3.15 \pm 0.40$ & 0.057 & $3.86 \pm 0.46$ & $3.69 \pm 0.39$ & 0.227 \\
\hline $\begin{array}{l}\text { Serum AST } \\
(U / L)\end{array}$ & $220 \pm 161$ & $254 \pm 168$ & 0.534 & $71.2 \pm 55.7$ & $84.1 \pm 35.0$ & 0.339 & $41.5 \pm 29.0$ & $36.1 \pm 14.3$ & 0.526 & $28.6 \pm 8.27$ & $46.0 \pm 22.4$ & 0.008 \\
\hline $\begin{array}{l}\text { Serum ALT } \\
(U / L)\end{array}$ & $147 \pm 117$ & $193 \pm 143$ & 0.303 & $94.4 \pm 66.2$ & $118.7 \pm 73.6$ & 0.300 & $55.8 \pm 48.1$ & $55.0 \pm 30.7$ & 0.940 & $22.0 \pm 8.50$ & $40.1 \pm 21.5$ & 0.004 \\
\hline $\begin{array}{l}\text { Prothrombin } \\
\text { time }(\%)\end{array}$ & $69.5 \pm 20.4$ & $65.5 \pm 10.9$ & 0.505 & $81.4 \pm 9.35$ & $77.6 \pm 13.4$ & 0.357 & $80.5 \pm 9.9$ & $94.7 \pm 118.7$ & 0.671 & $84.7 \pm 9.57$ & $76.3 \pm 14.5$ & 0.079 \\
\hline $\begin{array}{l}\text { Platelet } \\
\left(\times 10^{4} / \mu \mathrm{L}\right)\end{array}$ & $11.6 \pm 3.50$ & $11.8 \pm 3.17$ & 0.843 & $5.76 \pm 1.60$ & $12.1 \pm 3.38$ & 0.223 & $18.7 \pm 9.85$ & $15.7 \pm 4.78$ & 0.312 & $18.5 \pm 5.27$ & $15.3 \pm 4.80$ & 0.056 \\
\hline $\begin{array}{l}\text { C-reactive } \\
\text { protein } \\
(\mathrm{mg} / \mathrm{dL})\end{array}$ & - & - & & - & - & & $2.23 \pm 1.68$ & $2.48 \pm 2.05$ & 0.709 & $0.75 \pm 1.82$ & $0.41 \pm 0.63$ & 0.329 \\
\hline
\end{tabular}

AST: aspartate aminotransferase; ALT: alanine aminotransferase; AFP: alpha-fetoprotein; POD: post-operative day; POM: post-operative month

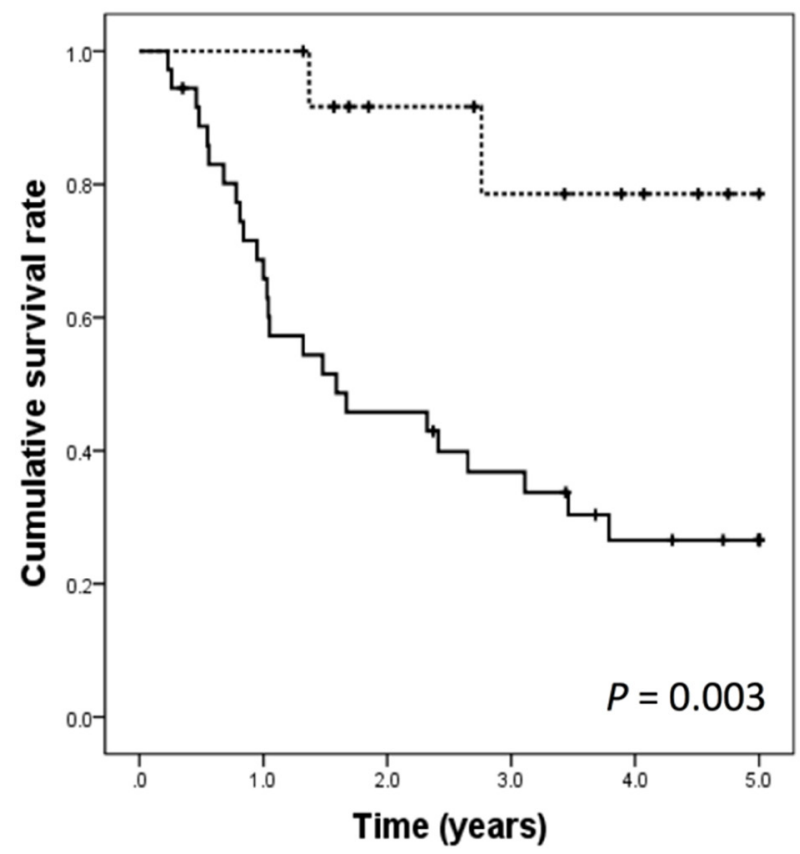

Figure 1. Disease-free survival curves after hepatic resection in the treatment group (dashed line) and the control groups (solid line)

potential. In the treatment group, the tumor marker levels decreased after chemotherapy, and the 5-year DFS and OS rates after surgery were improved significantly.

In this study, we administered short-term HAIC using a temporary indwelling catheter system. Almost all previous reports about neoadjuvant chemotherapy for HCC revealed that lesions were scheduled for TACE and that related complications such as liver function impairment or surgical delay sometimes made resectable tumors unresectable. HAIC is considered to cause fewer liver function complications than $\mathrm{TACE}^{[25-28]}$. In fact, this study illustrated that liver function was not adversely affected by neoadjuvant HAIC. 
Table 6. Histopathology of resected livers: treatment group versus control group

\begin{tabular}{|c|c|c|c|}
\hline Variables & Treatment group $(n=13)$ & Control group $(n=36)$ & $\boldsymbol{P}$ \\
\hline Tumor size $(\mathrm{mm})^{\star}$ & $27(14-50)$ & $25(10-58)$ & 0.666 \\
\hline Number of tumor $(n)^{\star}$ & $1.0(1-2)$ & $1.0(1-3)$ & 0.560 \\
\hline Microscopic vascular invasion & 3 & 18 & 0.131 \\
\hline Intrahepatic metastasises & 5 & 10 & 0.476 \\
\hline \multicolumn{4}{|l|}{ Gross classification } \\
\hline SN/SNEG/CMN & $4 / 4 / 4$ & $7 / 21 / 8$ & 0.535 \\
\hline Histologic grade & & & 0.202 \\
\hline Well differentiated & 1 & 1 & \\
\hline Moderately differentiated & 8 & 32 & \\
\hline Poorly differentiated & 3 & 3 & \\
\hline Liver cirrhosis ${ }^{\star \star}$ & & & 0.227 \\
\hline FO & 2 & 3 & \\
\hline F1-F2 & 6 & 8 & \\
\hline F3-F4 & 5 & 25 & \\
\hline \multicolumn{4}{|l|}{$\mathrm{JBCS}$} \\
\hline Grade 0 & 3 & - & \\
\hline Grade $1(1 \mathrm{a} / 1 \mathrm{~b})$ & $3 / 3$ & - & \\
\hline Grade $2(2 a / 2 b)$ & $2 / 1$ & - & \\
\hline Grade 3 & 1 & - & \\
\hline
\end{tabular}

${ }^{\star}$ Median with range; ${ }^{\star \star}$ new Inuyama classification. SN: simple nodular type; SNEG: simple nodular type with extranodular growth; CMN: confluent mutinodular type; JBCS: Japanese Brest Cancer Society

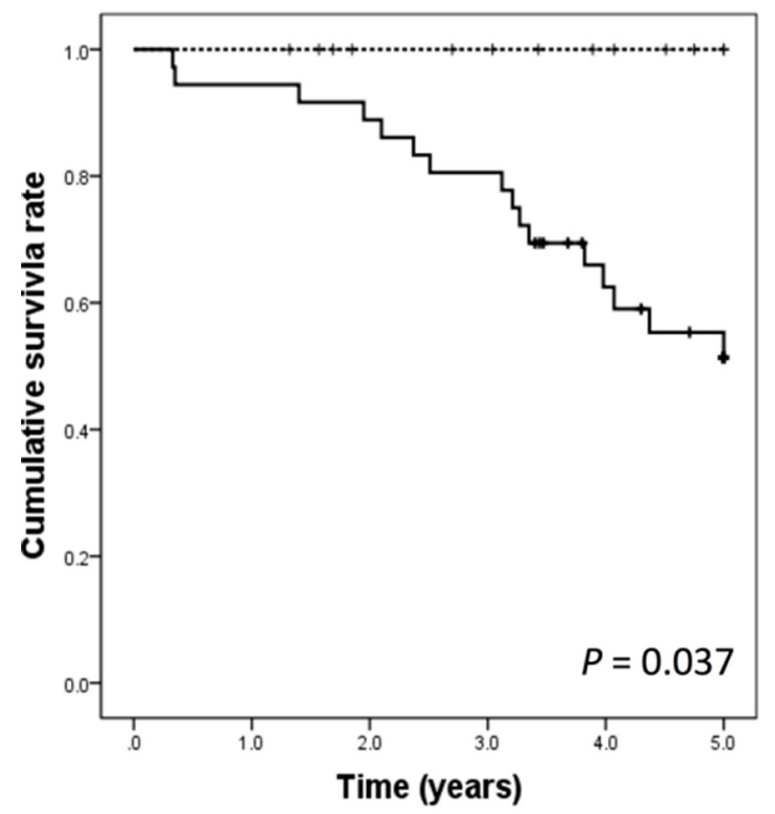

Figure 2. Overall survival curves after hepatic resection in the treatment group (dashed line) and the control groups (solid line)

The regimen selected for this study was 2 weeks of low-dose FP. Ishikawa et al. ${ }^{[29,30]}$ first reported that HAIC with cisplatin before radical local treatment (radiofrequency ablation/percutaneous ethanol injection therapy) for early-stage HCC prevented intrahepatic metastasis and prolonged the survival time. According to some clinical studies, the efficacy of low-dose FP is better than that of cisplatin alone ${ }^{[28]}$. Ueshima et al. ${ }^{[31]}$ reported that HAIC using low-dose FP (continuous arterial infusion of 5-FU and cisplatin for the first 2 weeks followed by a single dose of cisplatin and 5-FU once a week) is an effective treatment for locally advanced HCC. In our experience, almost all HAIC responders exhibited a decrease in tumor marker ratios in the early stage of treatment; thus, we believe 2 weeks of low-dose FP was sufficient to observe the effect of chemotherapy. HAIC-related liver toxicity is caused by complications associated with catheter placement, such as catheter dislocation, hepatic artery occlusion and stenosis, and infection. The 2-week regimen 
Table 7. Univariate and multivariate analysis of the prognostic predictors of disease-free survival

\begin{tabular}{|c|c|c|c|c|c|c|}
\hline Variables & Condition & $95 \% \mathrm{Cl}$ & $\boldsymbol{P}$ & HR & $95 \% \mathrm{Cl}$ & $\boldsymbol{P}$ \\
\hline Age (years) & $\begin{array}{l}>70 \\
\leq 70\end{array}$ & $\begin{array}{l}2.971-4.335 \\
1.296-2.684\end{array}$ & 0.002 & 0.374 & $0.166-0.842$ & 0.017 \\
\hline Gender & $\begin{array}{l}\text { Male } \\
\text { Female }\end{array}$ & $\begin{array}{l}2.064-3.300 \\
2.814-4.712\end{array}$ & 0.192 & & & \\
\hline Etiology & $\begin{array}{l}\text { Hepatitis B carrier } \\
\text { Hepatitis C carrier } \\
\text { Others }\end{array}$ & $\begin{array}{l}0.912-3.782 \\
2.485-3.769 \\
1.153-3.829\end{array}$ & 0.444 & & & \\
\hline AFP level $(\mathrm{ng} / \mathrm{mL})$ & $\begin{array}{l}>200 \\
\leq 200\end{array}$ & $\begin{array}{l}1.866-4.274 \\
2.242-3.454\end{array}$ & 0.699 & & & \\
\hline DCP level $(\mathrm{ng} / \mathrm{mL})$ & $\begin{array}{l}>400 \\
\leq 400\end{array}$ & $\begin{array}{l}1.546-4.097 \\
2.276-3.433\end{array}$ & 0.684 & & & \\
\hline Tumor diameter $(\mathrm{cm})$ & $\begin{array}{l}\geq 3 \\
<3\end{array}$ & $\begin{array}{l}1.853-3.750 \\
2.342-3.644\end{array}$ & 0.766 & & & \\
\hline Tumor number & $\begin{array}{l}>3 \\
\leq 3\end{array}$ & $\begin{array}{l}2.609-3.716 \\
0.343-0.889\end{array}$ & $<0.001$ & 7.731 & $2.474-14.161$ & $<0.001$ \\
\hline Microvascular invasion & $\begin{array}{l}(+) \\
(-)\end{array}$ & $\begin{array}{l}3.383-3.684 \\
1.696-3.494\end{array}$ & 0.631 & & & \\
\hline Intrahepatic metastasis & $\begin{array}{l}(+) \\
(-)\end{array}$ & $\begin{array}{l}1.145-3.178 \\
2.571-3.805\end{array}$ & 0.094 & & & \\
\hline Differentiation grade & $\begin{array}{l}\text { Poor } \\
\text { Others }\end{array}$ & $\begin{array}{l}1.345-4.292 \\
2.303-3.481\end{array}$ & 0.832 & & & \\
\hline Neoadjuvant HAIC & $\begin{array}{l}(+) \\
(-)\end{array}$ & $\begin{array}{l}3.662-5.147 \\
1.783-2.988\end{array}$ & 0.003 & 0.215 & $0.050-0.928$ & 0.039 \\
\hline Liver cirrhosis & $\begin{array}{l}(+) \\
(-)\end{array}$ & $\begin{array}{l}1.854-3.511 \\
2.352-3.775\end{array}$ & 0.482 & & & \\
\hline TNM pathological staging & $\begin{array}{l}\text { I } \\
\text { II } \\
\text { IIIA }\end{array}$ & $\begin{array}{l}2.529-6.953 \\
4.209-7.588 \\
0.545-0.545\end{array}$ & 0.058 & & & \\
\hline
\end{tabular}

HAIC: hepatic arterial infusion chemotherapy; AFP: alpha-fetoprotein; DCP: des-gamma-carboxyprothrombin; TNM: tumor nodes metastasis [6th edition of the American Joint Committee on Cancer (AJCC) staging]

enabled us to use a temporary indwelling catheter system, and after the administration of chemotherapy, the catheter system was removed easily under fluoroscopic guidance. In this study, the complication rate related to the temporary indwelling catheter system was also low.

Our data demonstrated the definitive improvements of DFS and OS after HAIC. There are two predicted reasons for this effect: (1) prevention of tumor cell dissemination during surgery, and (2) effectiveness in eradicating undetectable intrahepatic metastases. Concerning adjuvant HAIC, 2 non-randomized control trials reported that adjuvant HAIC after hepatic resection for HCC with macroscopic vascular invasion might reduce the risk of recurrence ${ }^{[32,33]}$. However, among patients with $\mathrm{Vp} 2$ or invasion of the main trunk of the hepatic vein (Vv2), the 3-year DFS and OS rates were not significantly different between the 2 groups ${ }^{[33]}$. Dislodging of tumor cells during surgery is considered one of the main causes of postoperative intrahepatic metastasis ${ }^{[3,35]}$; thus, neoadjuvant HAIC is theoretically effective for preventing tumor cells from dislodging and disseminating into the portal venous stream.

In the present study, complete necrosis (grade 3) was observed in 1 patient, and a shift from a viable tumor lesion to necrosis (grade 1a, 1b, 2a or 2b) was noted in 9 patients. Even when a pathomorphologic therapeutic effect did not appear in the main tumor, the effect of the chemotherapeutic agent might contribute to the suppression of cellular motility and invasiveness, facilitating the eradication of undetected intrahepatic metastases.

Multivariate analysis revealed that neoadjuvant HAIC was one of the independent favorable prognostic factors for DFS. However, there are several limitations to this study. First, our study was retrospective in nature and some biases may be present, including selection biases leading to the overestimation of the apparent importance of preoperative HAIC. Second, the sample seize was still small $(n=13)$. Although 
we think that effective adjuvant therapy in addition to preoperative HAIC is crucial for further improved prognosis, we could not show the sufficient efficacy of adjuvant chemotherapy. Further prospective multicenter trials are required to establish the effectiveness of neoadjuvant HAIC for the treatment of HCC.

In conclusion, neoadjuvant HAIC for patients with HCC with a high-grade malignant phenotype decreases the risk of recurrence and improves survival without serious complications. However, a prospective randomized study is required to confirm our findings.

\section{DECLARATIONS}

\section{Author's contributions}

Conceived of the presented idea and developed theory: Tsutsui R, Nagamatsu H, Itano O

Contributed to the interpretation of the results: Deguchi A, Tsutsumi T, Hiraki M, Mizukami N, Akiba J

Provided critical feedback and helped shape the research, analysis and manuscript: Tsutsui R, Nagamatsu H, Itano O, Deguchi A, Tsutsumi T, Hiraki M, Mizukami N, Akiban J

\section{Data source and availability}

The data presented is original and obtained in our laboratory. It is available with the authors and can be made available if required.

\section{Financial support and sponsorship}

None.

\section{Conflicts of interest}

There are no conflicts of interest.

\section{Patient consent}

Written informed consent from all the patients of the treatment group was obtained as part of the involvement in this study.

\section{Ethics approval}

The study was reviewed and approved by the Yame General Hospital Institutional Review Board.

\section{Copyright}

(c) The Author(s) 2018.

\section{REFERENCES}

1. European Association for the Study of the Liver; European Organisation for Research and Treatment of Cancer. EASL-EORTC clinical practice guidelines: management of hepatocellular carcinoma. J Hepatol 2012;56:908-43.

2. Hasegawa K, Kokudo N, Imamura H, Matsuyama Y, Aoki T, Minagawa M. Prognostic impact of anatomic resection for hepatocellular carcinoma. Ann Surg 2005;242:252-9.

3. Belghiti J, Panis Y, Farges O, Benhamou JP, Fekete F. Intrahepatic recurrence after resection of hepato- cellular carcinoma complicating cirrhosis. Ann Surg 1991;214:114-7.

4. Fan ST, Ng IO, Poon RT, Lo CM, Liu CL, Wong J. Hepatectomy for hepatocellular carcinoma: the surgeon's role in long-term survival. Arch Surg 1999;134:1124-30.

5. Imamura H, Matsuyama Y, Miyagawa Y, Ishida K, Shimada R, Miyagawa S, Makuuchi M, Kawasaki S. Prognostic significance of anatomical resection and des- $\gamma$-carboxy prothrombin in patients with hepatocellular carcinoma. Br J Surg 1999;86:1032-8.

6. Chan KM, Yu MC, Wu TJ, Lee CF, Chen TC, Lee WC, Chen MF. Efficacy of surgical resection in management of isolated extrahepatic metastases of hepatocellular carcinoma. World J Gastroenterol 2009;15:5481-8.

7. Taketomi A, Toshima T, Kitagawa D, Motomura T, Takeishi K, Mano Y, Kayashima H, Sugimachi K, Aishima S, Yamashita Y, Ikegami T, Gion T, Uchiyama H, Soejima Y, Maeda T, Shirabe K, Maehara Y. Predictors of extrahepatic recurrence after curative hepatectomy for hepato- cellular carcinoma. Ann Surg Oncol 2010;17:2740-6.

8. Lopez PM, Villanueva A, Llovet JM. Systematic review: evidence-based management of hepatocellular carcinoma - an updated analysis of randomized controlled trials. Aliment Pharmacol Ther 2006;23:1535-47. 
9. Llovet JM, Schwartz M, Mazzaferro V. Resection and liver transplantation for hepatocellular carcinoma. Semin Liver Dis 2005;25:181-200.

10. Kamiyama T, Nakanishi K, Yokoo H, Kamachi H, Tahara M, Kakisaka T, Tsuruga Y, Todo S, Taketomi A. Analysis of the risk factors for early death due to disease recurrence or progression within 1 year after hepatectomy in patients with hepatocellular carcinoma. World J Surg Oncol 2012;10:107-11.

11. Imamura H, Matsuyama Y, Tanaka E, Ohkubo T, Hasegawa K, Miyagawa S, Sugawara Y, Minagawa M, Takayama T, Kawasaki S, Makuuchi M. Risk factors contributing to early and late phase intrahepatic recurrence of hepatocellular carcinoma after hepatectomy. $J$ Hepatol 2003;38:200-7.

12. Arii S, Tanaka J, Yamazoe Y, Minematsu S, Morino T, Fujita K, Maetani S, Tobe T. Predictive factors for intrahepatic recurrence of hepatocellular carcinoma after partial hepatectomy. Cancer 1992;69:913-9.

13. Sumie S, Kuromatsu R, Okuda K, Ando E, Takata A, Fukushima N, Watanabe Y, Kojiro M, Sata M. Microvascular invasion in patients with hepatocellular carcinoma and its predictable clinicopathological factors. Ann Surg Oncol 2008;15:1375-82.

14. Chen XP, Hu DY, Zhang ZW, Zhang BX, Chen YF, Zhang WG, Qiu FZ. Role of mesohepatectomy with or without transcatheter arterial chemoembolization for large centrally located hepatocellular carcinoma. Dig Surg 2007;24:208-13.

15. Minagawa M, Makuuchi M, Takayama T, Ohtomo K. Selection criteria for hepatectomy in patients with hepatocellular carcinoma and portal vein tumor thrombus. Ann Surg 2001;233:379-84.

16. Sugo H, Futagawa S, Beppu T, Fukasawa M, Kojima K. Role of preoperative transcatheter arterial chemoembolization for resectable hepatocellular carcinoma: relation between postoperative course and the pattern of tumor recurrence. World J Surg 2003;27:1295-9.

17. Kaibori M, Tanigawa N, Matsui Y, Saito T, Uchida Y, Ishizaki M, Tanaka H, Kamiyama Y. Influence of transcatheter arterial chemoembolization on the prognosis after hepatectomy for hepatocellular carcinoma in patients with severe liver dysfunction. Anticancer Res 2006;26:3685-92.

18. Wu CC, Ho YZ, Ho WL, Wu TC, Liu TJ, Peng FK. Preoperative transcatheter arterial chemoembolization for resectable large hepatocellular carcinoma: a reappraisal. Br J Surg 1995;82:122-6.

19. Yamasaki S, Hasegawa H, Kinoshita H, Furukawa M, Imaoka S, Takasaki K, Kakumoto Y, Saitsu H, Yamada R, Oosaki Y, Arii S, Okamoto E, Monden M, Ryu M, Kusano S, Kanematsu T, Ikeda K, Yamamoto M, Saoshiro T, Tsuzuki T. A prospective randomized trial of the preventive effect of pre-operative transcatheter arterial embolization against recurrence of hepatocellular carcinoma. Jpn J Cancer Res 1996;87:206-11.

20. Liver Cancer Study Group of Japan. The general rules for the clinical and pathological study of primary liver cancer. Tokyo: Kanehara; 2008. p. 121-2.

21. Llovet JM, Bru C, Bruix J. Prognosis of hepatocellular carcinoma: the BCLC staging classification. Semin Liver Dis 1999;31:133-41.

22. Llovet JM, Di Bisceglie AM, Bruix J, Kramer BS, Lencioni R, Zhu AX, Sherman M, Schwartz M, Lotze M, Talwalkar J, Gores GJ; Panel of Experts in HCC-Design Clinical Trials. Design and endpoints of clinical trials in hepatocellular carcinoma. J Natl Cancer Inst 2008;100:698-711.

23. Nagaoka S, Itano S, Nagamatsu H, Akiyoshi J, Kurogi J, Tajiri N, Kajiwara M, Sata M. Temporary indwelling catheter system via the left brachial artery: evaluation in 83 patients with hepatic tumors. AJR Am J Roentgenol 2007;188:652-8.

24. Horii R, Akiyama F. Histological assessment of therapeutic response in breast cancer. Breast Cancer 2016;23:540-5.

25. Xue TC, Xie XY, Zhang L, Yin X, Zhang BH, Ren ZG. Transarterial chemoembolization for hepatocellular carcinoma with portal vein tumor thrombus: a meta-analysis. BMC Gastroenterol 2013;13:60.

26. Ando E, Tanaka M, Yamashita F, Kuromatsu R, Yutani S, Fukumori K, Sumie S, Yano Y, Okuda K, Sata M. Hepatic arterial infusion chemotherapy for advanced hepatocellular carcinoma with portal vein tumor thrombosis: analysis of 48 cases. Cancer 2002;95:588-95.

27. Miyaki D, Kawaoka T, Aikata H, Kan H, Fujino H, Fukuhara T, Kobayashi T, Naeshiro N, Honda Y, Tsuge M, Hiramatsu A, Imamura M, Hyogo H, Kawakami Y, Yoshimatsu R, Yamagami T, Awai K, Chayama K. Evaluation of early response to hepatic arterial infusion chemotherapy in patients with advanced hepatocellular carcinoma using the combination of response evaluation criteria in solid tumors and tumor markers. J Gastroenterol Hepatol 2015;30:726-32.

28. Ueda H, Fukuchi H, Tanaka C. Toxicity and efficacy of hepatic arterial infusion chemotherapy for advanced hepatocellular carcinoma. Oncol Lett 2012;3:259-63.

29. Ishikawa T, Higuchi K, Kubota T, Seki K, Honma T, Yoshida T, Kamimura T. Prevention of intrahepatic distant recurrence by transcatheter arterial infusion chemotherapy with platinum agents for stage I/II hepatocellular carcinoma. Cancer 2011;117:4018-25.

30. Ishikawa T, Kubota T, Abe S, Watanabe Y, Sugano T, Inoue R, Iwanaga A, Seki K, Honma T, Yoshida T. Hepatic arterial infusion chemotherapy with cisplatin before radical local treatment of early hepatocellular carcinoma (JIS score 0/1) improves survival. Ann Oncol 2014;25:1379-84.

31. Ueshima K, Kudo M, Takita M, Nagai T, Tatsumi C, Ueda T, Kitai S, Ishikawa E, Yada N, Inoue T, Hagiwara S, Minami Y, Chung H. Hepatic arterial infusion chemotherapy using low-dose 5-fluorouracil and cisplatin for advanced hepatocellular carcinoma. Oncology 2010;78:148-53.

32. Nagano H, Kobayashi S, Marubashi S, Wada H, Eguchi H, Tanemura M, Tomimaru Y, Umeshita K, Doki Y, Mori M. Combined IFN- $\alpha$ and 5-FU treatment as a postoperative adjuvant following surgery for hepatocellular carcinoma with portal venous tumor thrombus. Exp Ther Med 2013;5:3-10.

33. Nitta H, Beppu T, Imai K, Hayashi H, Chikamoto A, Baba H. Adjuvant hepatic arterial infusion chemotherapy after hepatic resection of hepatocellular carcinoma with macroscopic vascular invasion. World J Surg 2013;37:1034-42.

34. Yamanaka N, Okamoto E, Fujihara S, Kato T, Fujimoto J, Oriyama T, Mitsunobu M, Toyosaka A, Uematsu K, Yamamoto K. Do the tumor cells of hepatocellular carcinomas dislodge into the portal venous stream during hepatic resection? Cancer 1992;70:2263-7.

35. Wong IH, Lau WY, Leung T, Yeo W, Johnson PJ. Hematogenous dissemination of hepatocytes and tumor cells after surgical resection of hepatocellular carcinoma: a quantitative analysis. Clin Cancer Res 1999;5:4021-7. 